\title{
Current Concepts of Prolotherapy in Orthopedic Surgery
}

\author{
Serkan Akpancar, ${ }^{1, *}$ Mehmet Murat Seven, ${ }^{2}$ Harun Yasin Tuzun, ${ }^{1}$ Levent Gurer, ${ }^{1}$ and Safak Ekinci ${ }^{3}$ \\ ${ }^{1}$ Department of Orthopedic Surgery, Gulhane Military Medicine Academy, Ankara, Turkey \\ ${ }^{2}$ Department of Sports Medicine, Gulhane Military Medicine Academy, Ankara, Turkey \\ ${ }^{3}$ Department of Orthopedic Surgery, Haydarpasa Gulhane Military Medicine Academy, Istanbul, Turkey \\ "Corresponding author: Serkan Akpancar, Department of Orthopedic Surgery, Gulhane Military Medicine Academy, Ankara, Turkey. Tel: +90-5443229700, Fax: +90-312 3045500, \\ E-mail: drserkanakpancar@gmail.com
}

Received 2016 June 28; Revised 2016 August 10; Accepted 2016 September 25.

\begin{abstract}
Context: Prolotherapy is a popular injection-based complementary treatment, which has shown promising results in the treatment of sprained and degenerated ligaments, and damaged dense connective tissues' structures. More research was conducted in this area and many authors declared successful results for different indications.

Evidence Acquisition: The purpose of this study was to present a literature review regarding the current concepts of prolotherapy injections and improvements in the orthopedic clinical care practice. The Medline and PubMed databases were searched for the articles related to prolotherapy injections in the field of orthopedic surgery and additionally the reference list of each article was also included to provide a comprehensive evaluation.

Results: Numerous studies have been conducted on prolotherapy injections for different indications for orthopedics clinical care practice. Prolotherapy injections have successfully used for major orthopedic procedures in terms of rotator cuff lesions, knee ligamentous lesions, osteoarthritis-cartilage defects, and ligament-tendon injuries. Most of the studies showed that prolotherapy provided faster and better healing of tissues.

Conclusions: There is a great interest to prolotherapy in orthopedic clinics, especially to manage musculoskeletal lesions. More research conducted in this area and many authors declared successful results in their studies. In spite of this increasing trend for prolotherapy injections, there were only one or two clinical studies investigated prolotherapy injections for different indications and most of them have limited participants, short-term follow-up or poor quality studies. There is still need for further high-quality studies investigated optimal strategy of the injections of prolotherapy.
\end{abstract}

Keywords: Prolotherapy Injections, Preparation Protocols of Prolotherapy, Current Indications of Prolotherapy

\section{Context}

Musculoskeletal injuries are very common, and one of the global health problems. Numerous research have been conducted into this area; however, there is still controversy about the most effective method (1-3).

In recently prolotherapy has successfully used in the treatment of sprained and degenerated ligaments, damaged dense connective tissues structures including tendons and enthesis, chondromalacia patella and osteoarthritis (4-10). Too many advantages exist with this method; including easy application, shortening the rehabilitation process and cost effectiveness. It also provides healing of the structures (ligaments and tendons) then; stability and functionality of the tissues are restored (11).

Prolotherapy injections are prepared with distinct concentrations of hypertonic dextrose. The solutions are injected to specific regions of the effected body part, and then provide the osmotic rupture of local cells (12). This leads to an increase of glucose in the extracellular matrix, which increases growth factors and causes deposition of new collagen into different types of human cells and sub- sequent healing (13-16).

\section{Evidence Acquisition}

The aim of this study was to present a systemic review regarding the most recent progress in prolotherapy injections and current indications in orthopedic clinical care practice. The Medline and PubMed databases (1946 to the 30th of May 2016) were searched for the articles related with prolotherapy in the field of orthopedic surgery and additionally the reference list of each article was also included to provide a comprehensive evaluation.

\subsection{Inclusion Criteria}

In this study, English-language clinical studies (case reports, case series, randomized and nonrandomized clinical studies) related with prolotherapy methods in orthopedic surgery were included. Every form of prolotherapy components (e.g., dextrose or sodium morrhuate) was included, and there was no limitation in preparing the process of prolotherapy. Because of the lack of relevant, matching studies, there was no limitation in comparators. 


\subsection{Exclusion Criteria}

Studies evaluating different treatment methods other than prolotherapy injections, prolotherapy procedures nonrelated with the orthopedic surgery, and nonclinical study types (e.g., systemic reviews, meta-analysis, animal studies, and cadaver studies) were excluded from the study.

The search results accounted for 135 articles. Sixtythree articles were excluded from the study because of nonrelevant topics, thus 72 articles were included in the study. Thirty articles were clinical studies, 3 articles were animal studies, and 39 articles were reviews and other study types. The article selection process was shown in Figure 1.

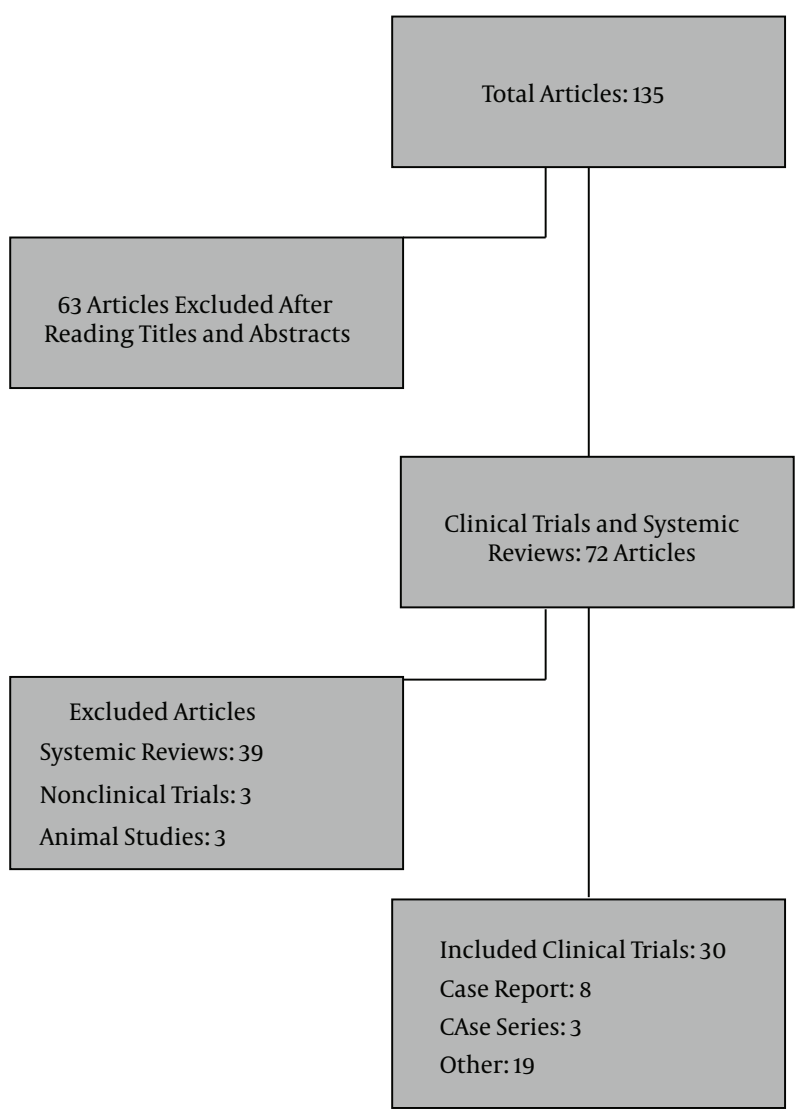

Figure 1. Article Selection Process

\section{Results}

\subsection{Preparation Protocols of Prolotherapy}

There is no standard protocol for preparation of prolotherapy solutions. Different concentrations and combinations of prolotherapy solutions used in the literature for different indications. Concentration of dextrose differs from five to twenty-five percent and the optimal concentration remains obscure $(17,18)$. Jensen $\mathrm{K}$ et al. (19, 20) stated that dextrose solutions below the concentration of $10 \%$ stimulate proliferation of cells and tissue but do not have a significant effect on histological inflammatory reaction with these concentrations. When dextrose is injected in greater than the concentration of $10 \%$, osmotic (concentrated) gradient stimulates accumulation of growth factors and inflammatory cells that initiates the wound-healing cascade. Therefore, the concentrations of dextrose greater than $10 \%$ should be preferred for proliferation and histological inflammatory reaction.

In combination with dextrose, different concentrations of lidocaine, sensorcaine and xylocaine were the most used pharmaceutical agents (20-22). There was no animal or clinical study in the literature that compared the effectiveness of different concentrations or combinations of prolotherapy solutions $(12,19)$. Therefore, there is a need for further studies investigated optimal strategy of the injections of prolotherapy.

\subsubsection{Number and Interval of Injection Sessions}

The number and interval of injection sessions are also different in the studies; some authors preferred single, others preferred serial sessions, therefore number and interval of injection sessions depend on experience and local practice patterns. Prolotherapy is an invasive treatment method and repeated injection sessions seem to be excessive and costly. In the previous studies that investigated efficacy of prolotherapy in the treatment of various musculosketal conditions, at least three injection sessions were performed. Moreover, some of the studies declared that most effective benefits could be gained with repeated injections $(13,23-27)$.

\subsubsection{Injection Procedures}

Prolotherapy injections can be performed with palpation or ultrasound-guided. Chen et al. (28) compared ultrasound-guided and palpation guided injection in the treatment of plantar fasciitis and stated that therapeutic outcomes were significantly better with ultrasoundguided injection than palpation-guided injection. They also stated that effectiveness and duration might increase with the precise injections into the target points. They also observed higher rates of recurrence with palpationguided injections (29). Because of the anti-inflammatory effects, NSAIDs counteract the pro-inflammatory mechanism; therefore, all NSAIDs should be stopped 2 - 3 weeks prior to a prolotherapy procedure and then no NSAIDs are used for the duration of treatment with prolotherapy. 
There is no consensus regarding the volume of prolotherapy solutions. In the previous studies, 2 cc to $4 \mathrm{cc}$ of prolotherapy injected to every painful points $(6,8,9,13)$.

\subsection{Main Indications of Prolotherapy in Orthopedic Surgery}

\subsubsection{Knee Osteoarthritis}

Knee osteoarthritis (OA) is a chronic joint disease; characterized by knee pain, stiffness, and functional impairment. Many studies are available about efficiency about prolotherapy injections in the treatment of osteoarthritis. Most of these studies have shown beneficial effects of prolotherapy injections in terms of improvement in pain scales (between $36 \%$ to $55 \%$ improvement) and WOMAC subscales (30-33). Injection sites varies according to studies; some authors were performed combined intra-articular and extra-articular injection for bony attachments of LCL or other ligaments, some preferred single intra-articular injection. The first seemed to be more promising method for patients with ligament injury in the younger ages, and also elderly patients with knee OA and have extra-articular degenerated ligaments. Mechanic instability commonly occurs in patients with osteoarthritis due to injury or degeneration of knee ligaments. The studies evaluated prolotherapy injections to the osteoarthritic patients with traumatic knee instability have shown beneficial outcomes in terms of decreasing pain and healing knee ligaments that provide mechanic stability of knee joint. In these studies favorable results of prolotherapy have shown in terms of improvements of cartilage defects and healing of extra-articular injured ligaments $(22,34)$. Rabago et al. (43 investigated long-term outcomes (mean of 2.5 years) of prolotherapy in the patients with mild-tosevere knee OA in an open-label follow-up study. Prolotherapy injections were resulted significant improvements in terms of knee functions, pain intensity, and stiffness. Its effect has been shown to be better than saline injections and pulsed radiofrequency in the randomized and controlled studies $(30,35)$. No significant difference was found between prolozone and prolotherapy in a randomized clinical trial (9). Also, $12.5 \%$ to $20 \%$ of dextrose concentrations were used in the studies and success rates were similar, thus 12.5 of dextrose may be used for osteoarthritis $(8,9$, $22,30-36)$. As prolotherapy is a simple, rapid, and safe option, it can be considered a first-line conservative therapy for knee OA.

\subsubsection{Chondromalacia Patella}

Chondromalacia patella is one of the most common diseases of knee accompanied by chronic pain and dysfunction. The disease is defined as the degeneration, and thinning of the cartilage of the patella. The disease affects both younger and older patients and if it is not properly treated, it could be induced disruption of cartilage and eventually resultant osteoarthritis (37). In spite of recent treatment modalities including anti-inflammatory drugs, exercise, physical therapy, and corticosteroid injections, there is a need for new methods in some group patients. Hauser et al. (10) investigated the efficiency of prolotherapy in 61 patients with chondromalacia patella in their retrospective study. They faced successful results with prolotherapy injections in terms of enhancing the knee functions and pain relief. Despite the aforementioned studies, there is a need for prospective, randomized or controlled trials in this area.

\subsubsection{Epicondylitis}

Epicondylitis is a common cause of elbow pain in the middle ages. It is usually associated with repetitive and forceful activity believed to be a degenerative process, which stems from repetitive microtrauma (13). Prolotherapy is thought to be promising in this area; however, a few available studies declared contradictory results. Scarpone et al. (13) used prolotherapy injections in the treatment of chronic lateral epicondylitis with comparison of placebo of saline injections in a double-blind randomized controlled trial. In the prolotherapy group, pain intensity and grip strength were significantly improved up to a mean follow-up of 50 weeks. Then Carayannopoulos et al. (38) used prolotherapy injections with the comparison of corticosteroid injections in the treatment of lateral epicondylitis in another randomized controlled trial. They observed significant improvement at 3 or 6 months at both of the groups, and there was no significant difference between the groups. There is a still need for more randomized controlled studies have larger participants and have more objectively outcome measures. Most of the studies were conducted with lateral epicondylitis, therefore the efficiency of prolotherapy is not known yet.

\subsubsection{Rotator Cuff Lesions}

Rotator cuff lesions are very common in all age groups (39). A considerable number of patients can be healed with conservative methods; however, these may not be efficient in some group of patients, thus there is a need for new methods in these patients (40-42). Prolotherapy injections was firstly used by Lee et al. (43) in the nonrandomized retrospective case-control study. They observed that prolotherapy injections provide improvement in pain, disability, isometric strength, and shoulder motion in patients with refractory chronic rotator cuff disease resistant to conservative treatment. Then, Bertrand et al. (44) used prolotherapy in the treatment of rotator cuff tendinopathy in a randomized and controlled study with a control group, 
which were subjected of saline injections, and observed pain improvement and patient satisfaction, but there was no significant difference in the shoulder pathological healing when compared to the control group.

\subsubsection{Plantar Fasciitis}

Plantar fasciitis is a major cause of foot disability in the ages of 40 and 60 years $(45,46)$. Conservative treatment modalities are not effective in approximately $10 \%$ of the patients and there is a still need for more effective treatment modalities for this group of patients (47). There is limited evidence about prolotherapy in the treatment of plantar fasciitis. In the available literature, prolotherapy was only used by M B Ryan (48) in the treatment of chronic plantar fasciitis of 20 patients and found a significant decrease in VAS scores when compared to preoperative values, and they also determined good to excellent results in 16 of 20 patients (80\%). There is a need for randomized controlled trials, which have a larger number of participants in the area. Kim et al. comprised prolotherapy and platelet rich plasma in the treatment of chronic recalcitrant plantar fasciitis in a single-blinded, randomized, controlled study, and concluded that platelet rich plasma may lead to a better initial improvement in function, however all the two methods were effective and there was no significant difference between the groups (33).

\subsubsection{Knee Collateral Ligaments}

Collateral ligaments provide medial and lateral stability of the knee joint. They usually injured from direct trauma with varus and valgus stress (49). There is very limited evidence about prolotherapy in the treatment of collateral ligaments. In the literature there is only a case report accessed that gives evidence about prolotherapy injections in the treatment of MCL lesion of male rugby player sustained valgus stress to his knee (50). After 12 weeks of first prolotherapy injection he had no residual symptoms or functional deficit. Patient was evaluated with MRI sixth months after trauma and the MRI findings showed a well-healed, relatively homogeneous MCL and also subchondral bone marrow edema at the corner of the lateral tibial plateau had also diminished.

\subsubsection{Osteoarthritis of Carpometacarpal or Metatarsal Joints}

The symptomatic osteoarthritic hand is common over the ages of 70 and has been estimated as $13.4 \%$ for men and $26.2 \%$ for women (51). Corticosteroid injection is the most common method and showed benefits in the short- time period; however, its effectiveness was stated to be temporary by many authors in the long-term (52). Azadeh Jahangiri et al. (53) investigated prolotherapy in the treatment of osteoarthritis of the first carpometacarpal joint in a randomized clinical trial with comparison of corticosteroid injections. In the short-time ( 1 month), they showed that corticosteroid injections had better outcomes than prolotherapy. However, partial symptoms in the corticosteroid group were recurred in the long period (6 months) and the prolotherapy group had significantly better outcomes than the corticosteroid group in terms of functions and pain after 6 months of first treatment.

\subsection{Complications}

Prolotherapy is known to be safe method when compared to other injection based complementary methods. The studies reported very few complications including allergic reactions, superficial tissue infections and nerve damage (12). There is no risk for tendon rupture injecting in and around a tendinopathic tendon, this may occur when the tendon insertion is too weakened. It is presumed to be effective by stimulating weakened structures such as ligaments and tendons to strengthen, tighten and heal by the induced proliferation of cells $(54,55)$.

\subsection{Limitations}

Only two databases (The Medline and PubMed library) were searched for articles; it was seemed that only the positive findings of prolotherapy were presented and counterpoint articles were neglected in this review. However, most of the included articles had positive findings about prolotherapy injections. There may be some counterpoint articles in the non-English literature or the other articles indexed in other databases, leading selection bias. Screening references of identified case series and trials may result in an over representation of positive studies in this review, because trials with a positive result are more likely to be referred to in other publications, leading to reference bias.

\subsection{Conclusions}

In recently, there is a great interest to prolotherapy in sports medicine and orthopedic clinics, especially to manage chronic musculoskeletal system disorders. More research conducted in this area and many authors declared successful results. In the clinical practice its effectiveness was firstly showed in the painful overuse tendinopathies, by the time, it was used for osteoarthritis and successful clinical outcomes were obtained especially in the longperiods. In spite of new development knowledge about prolotherapy injections, there were only one or two clinical studies investigated prolotherapy injections for different indications and most of them have limited participants, short-term follow-up or poor quality studies. There is still need for further high-quality studies investigated optimal strategy of the injections of prolotherapy. 


\section{Footnote}

Authors' Contribution: All authors contributed to and approved the manuscript.

\section{References}

1. Kelsey J. Epidemiology of musculoskeletal disorders. New York: Oxford University Press; 1982.

2. Lawrence RC, Hochberg MC, Kelsey JL, McDuffie FC, Medsger TA, Felts WR, et al. Estimates of the prevalence of selected arthritic and musculoskeletal diseases in the United States. JRheumatol. 1989;16(4):427-41. [PubMed: 2746583].

3. Bilgic S, Durusu M, Aliyev B, Akpancar S, Ersen O, Yasar SM, et al. Comparison of two main treatment modalities for acute ankle sprain. PakJMed Sci. 2015;31(6):1496-9. doi:10.12669/pjms.316.8210. [PubMed: 26870123].

4. Distel LM, Best TM. Prolotherapy: a clinical review of its role in treating chronic musculoskeletal pain. PM R. 2011;3(6 Suppl 1):S78-81. doi: 10.1016/j.pmrj.2011.04.003. [PubMed: 21703585].

5. Taylor M. Prolotherapy for peripheral joints. Australasian Musculoskeletal Medicine. 2004;9(1):38.

6. Seven MM, Koca K, Akpancar S, Turkkan S, Uysal B, Yildiz Y, et al. Prolotherapy Injections in the Treatment of Overuse Injuries. BMMR. 2016;19(3):113-5.

7. Kannus P. Tendon pathology: basic science and clinical applications. Sports Exercise and Injury. 1997;3(2):62-75.

8. Rabago D, Mundt M, Zgierska A, Grettie J. Hypertonic dextrose injection (prolotherapy) for knee osteoarthritis: Long term outcomes. Complement Ther Med. 2015;23(3):388-95. doi: 10.1016/j.ctim.2015.04.003. [PubMed: 26051574].

9. Hashemi M, Jalili P, Mennati S, Koosha A, Rohanifar R, Madadi F, et al. The Effects of Prolotherapy With Hypertonic Dextrose Versus Prolozone (Intraarticular Ozone) in Patients With Knee Osteoarthritis Anesth pain med. 2015;5(5).

10. Hauser RA, Sprague IS. Outcomes of prolotherapy in chondromalacia patella patients: improvements in pain level and function. Clin Med Insights Arthritis Musculoskelet Disord. 2014;7:13-20. doi: 10.4137/CMAMD.S13098. [PubMed: 24596471].

11. Hackett GS, Hemwall GA, Montgomery GA. Ligament and Tendon Relaxation Treated by Prolotherapy. 1956 First Edition Charles C. Thomas, Publisher. Gustav A. Hemwall, Publisher. Institute in Basic Life Principles. Oak Brook, IL; 1991

12. Rabago D, Slattengren A, Zgierska A. Prolotherapy in primary care practice. Prim Care. 2010;37(1):65-80. doi: 10.1016/j.pop.2009.09.013. [PubMed: 20188998].

13. Scarpone M, Rabago D, Zgierska A, Arbogest J, Snell E. . The efficacy of prolotherapy for lateral epicondylosis: a pilot study. Clin J Sport Med. 2008;18(3):248-54. doi: 10.1097/JSM.0b013e318170fc87. [PubMed: 18469566].

14. Di Paolo S, Gesualdo L, Ranieri E, Grandaliano G, Schena FP. High glucose concentration induces the overexpression of transforming growth factor-beta through the activation of a plateletderived growth factor loop in human mesangial cells. Am J Pathol. 1996;149(6):2095-106. [PubMed: 8952542].

15. Murphy M, Godson C, Cannon S, Kato S, Mackenzie HS, Martin F, et al Suppression subtractive hybridization identifies high glucose levels as a stimulus for expression of connective tissue growth factor and other genes in human mesangial cells. J Biol Chem. 1999;274(9):58304. [PubMed: 10026205].

16. Krump E, Nikitas K, Grinstein S. Induction of tyrosine phosphorylation and $\mathrm{Na}+\mathrm{H}+$ exchanger activation during shrinkage of human neutrophils. J Biol Chem. 1997;272(28):17303-11. [PubMed: 9211867].
17. Lyftogt J. Subcutaneous prolotherapy treatment of refractory knee, shoulder, and lateral elbow pain. Australasian Musculoskeletal Med. 2007;12(2):110.

18. Reeves KD, Fullerton BD, Topol G. Evidence-based regenerative injection therapy (prolotherapy) in sports medicine.The Sports Medicine Resource Manual. Saunders (Elsevier); 2008. pp. 611-9.

19. Jensen KT, Rabago DP, Best TM, Patterson JJ, Vanderby R. Early inflammatory response of knee ligaments to prolotherapy in a rat model. J Orthop Res. 2008;26(6):816-23. doi: 10.1002/jor.20600. [PubMed: 18240327].

20. Jensen KT, Rabago DP, Best TM, Patterson JJ, Vanderby R. Response of knee ligaments to prolotherapy in a rat injury model. Am J Sports Med. 2008;36(7):1347-57. doi: 10.1177/0363546508314431. [PubMed: 18310313].

21. Reeves KD, Hassanein K. Randomized, prospective, placebocontrolled double-blind study of dextrose prolotherapy for osteoarthritic thumb and finger (DIP, PIP, and trapeziometacarpal) joints: evidence of clinical efficacy. J Altern Complement Med. 2000;6(4):311-20. doi: 10.1089/10755530050120673. [PubMed: 10976977].

22. Reeves KD, Hassanein K. Randomized prospective double-blind placebo-controlled study of dextrose prolotherapy for knee osteoarthritis with or without ACL laxity. Altern Ther Health Med. 2000;6(2):68-74. [PubMed: 10710805].

23. Dechow E, Davies RK, Carr AJ, Thompson PW. A randomized, doubleblind, placebo-controlled trial of sclerosing injections in patients with chronic low back pain. Rheumatology (Oxford). 1999;38(12):12559. [PubMed: 10587555].

24. Khan SA, Kumar A, Varshney MK, Trikha V, Yadav CS. Dextrose prolotherapy for recalcitrant coccygodynia. J Orthop Surg (Hong Kong). 2008;16(1):27-9. [PubMed: 18453654].

25. Miller MR, Mathews RS, Reeves KD. Treatment of painful advanced internal lumbar disc derangement with intradiscal injection of hypertonic dextrose. Pain Physician. 2006;9(2):115-21. [PubMed: 16703971].

26. Maxwell NJ, Ryan MB, Taunton JE, Gillies JH, Wong AD. Sonographically guided intratendinous injection of hyperosmolar dextrose to treat chronic tendinosis of the Achilles tendon: a pilot study. AJR Am J Roentgenol. 2007;189(4):W215-20. doi: 10.2214/AJR.06.1158. [PubMed: 17885034].

27. Holmich P, Uhrskou P, Ulnits L, Kanstrup IL, Nielsen MB, Bjerg AM, et al. Effectiveness of active physical training as treatment for longstanding adductor-related groin pain in athletes: randomised trial. Lancet. 1999;353(9151):439-43. doi: 10.1016/S0140-6736(98)03340-6. [PubMed: 9989713].

28. Chen CM, Chen JS, Tsai WC, Hsu HC, Chen KH, Lin CH. Effectiveness of device-assisted ultrasound-guided steroid injection for treating plantar fasciitis. Am J Phys Med Rehabil. 2013;92(7):597-605. doi: 10.1097/PHM.ob013e318278a831. [PubMed: 23221670].

29. Tsai WC, Hsu CC, Chen CP, Chen MJ, Yu TY, Chen YJ. Plantar fasciitis treated with local steroid injection: comparison between sonographic and palpation guidance. J Clin Ultrasound. 2006;34(1):12-6. doi: 10.1002/jcu.20177. [PubMed: 16353228].

30. Rabago D, Patterson JJ, Mundt M, Kijowski R, Grettie J, Segal NA, et al. Dextrose prolotherapy for knee osteoarthritis: a randomized controlled trial. Ann Fam Med. 2013;11(3):229-37. doi: 10.1370/afm.1504. [PubMed: 23690322].

31. Ekinci S, Tatar O, Akpancar S, Turgut H, Seven MM. A New Treatment Option in Osteoarthritis: Prolotherapy Injections. J Arthritis. 2016;5(197 in press).

32. Rabago D, Zgierska A, Fortney L, Kijowski R, Mundt M, Ryan M, et al. Hypertonic dextrose injections (prolotherapy) for knee osteoarthritis: results of a single-arm uncontrolled study with 1-year follow-up. J Altern Complement Med. 2012;18(4):408-14. doi: 10.1089/acm.2011.0030. [PubMed: 22515800].

33. Kim J. The effect of prolotherapy for osteoarthritis of the knee. J Korean Acad Rehabil Med. 2002;26:445-8. 
34. Reeves KD, Hassanein KM. Long-term effects of dextrose prolotherapy for anterior cruciate ligament laxity. Altern Ther Health Med. 2003;9(3):58-62. [PubMed: 12776476].

35. Rahimzadeh P, Imani F, Faiz SH, Entezary SR, Nasiri AA, Ziaeefard M. Investigation the efficacy of intra-articular prolotherapy with erythropoietin and dextrose and intra-articular pulsed radiofrequency on pain level reduction and range of motion improvement in primary osteoarthritis of knee. J Res Med Sci. 2014;19(8):696-702. [PubMed: 25422652].

36. Felson DT. An update on the pathogenesis and epidemiology of osteoarthritis. Radiologic Clinics of North America. 2004;42(1):1-9. doi: 10.1016/s0033-8389(03)00161-1.

37. Wheaton $\mathrm{M}$, Jensen $\mathrm{N}$. The ligament injury connection to osteoarthritis. Journal of Prolotherapy. 2010;2(1):294-304.

38. Carayannopoulos A, Borg-Stein J, Sokolof J, Meleger A, Rosenberg D. Prolotherapy versus corticosteroid injections for the treatment of lateral epicondylosis: a randomized controlled trial.PMR. 2011;3(8):70615. doi: 10.1016/j.pmrj.2011.05.011. [PubMed: 21871414].

39. Baker CL. Shoulder impingement and rotator cuff lesions. The Hughston Clinic Sports Medicine Book. Baltimore. United States: Md: Lippincott Williams and Wilkins; 1995.

40. Bishay V, Gallo RA. The evaluation and treatment of rotator cuff pathology. Prim Care. 2013;40(4):889-910. doi: 10.1016/j.pop.2013.08.006. [PubMed: 24209724].

41. Wilson JJ, Best TM. Common overuse tendon problems: A review and recommendations for treatment. Am Fam Physician. 2005;72(5):811-8. [PubMed: 16156339].

42. Seven MM, Koca K, Akpancar S, Turkkan S, Uysal B, Yildiz Y, et al Promising Results of Prolotherapy in an Elderly Male with Bilateral Partial Rotator Cuff Lesions. BMMR. 2016.

43. Lee DH, Kwack KS, Rah UW, Yoon SH. Prolotherapy for Refractory Rotator Cuff Disease: Retrospective Case-Control Study of 1Year Follow-Up. Arch Phys Med Rehabil. 2015;96(11):2027-32. doi: 10.1016/j.apmr.2015.07.011. [PubMed: 26254952].

44. Bertrand H, Reeves KD, Bennett CJ, Bicknell S, Cheng AL. Dextrose Prolotherapy Versus Control Injections in Painful Rotator Cuff Tendinopathy. Arch Phys Med Rehabil. 2016;97(1):17-25. doi: 10.1016/j.apmr.2015.08.412. [PubMed: 26301385].

45. Riddle DL, Pulisic M, Sparrow K. Impact of demographic and impairment-related variables on disability associated with plantar fasciitis. Foot Ankle Int. 2004;25(5):311-7. [PubMed: 15134611]

46. Tu P, Bytomski JR. Diagnosis of heel pain. Am Fam Physician. 2011;84(8):909-16. [PubMed: 22010770].

47. Davis PF, Severud E, Baxter DE. Painful heel syndrome: results of nonoperative treatment. Foot Ankle Int. 1994;15(10):531-5. [PubMed: 7834059].

48. Ryan MB, Wong AD, Gillies JH, Wong J, Taunton JE. Sonographically guided intratendinous injections of hyperosmolar dextrose/lidocaine: a pilot study for the treatment of chronic plantar fasciitis. Br J Sports Med. 2009;43(4):303-6. doi: 10.1136/bjsm.2008.050021. [PubMed:19019908].

49. Griffith CJ, LaPrade RF, Johansen S, Armitage B, Wijdicks C, Engebretsen L. Medial knee injury: Part 1, static function of the individual components of the main medial knee structures. Am J Sports Med. 2009;37(9):1762-70. doi: 10.1177/0363546509333852. [PubMed: 19609008].

50. Ada AM, Yavuz F. Treatment of a medial collateral ligament sprain using prolotherapy: a case study. Altern Ther Health Med. 2015;21(4):68-71 [PubMed: 26030118]

51. Zhang Y, Niu J, Kelly-Hayes M, Chaisson CE, Aliabadi P, Felson DT. Prevalence of symptomatic hand osteoarthritis and its impact on functional status among the elderly: The Framingham Study. Am J Epidemiol. 2002;156(11):1021-7. [PubMed: 12446258].

52. Joshi R. Intraarticular corticosteroid injection for first carpometacarpal osteoarthritis. J Rheumatol. 2005;32(7):1305-6. [PubMed: 15996069].

53. Jahangiri A, Moghaddam FR, Najafi S. Hypertonic dextrose versus corticosteroid local injection for the treatment of osteoarthritis in the first carpometacarpal joint: a double-blind randomized clinical trial. J Orthop Sci. 2014;19(5):737-43. doi: 10.1007/s00776-014-0587-2. [PubMed: 25158896].

54. Liu YK, Tipton CM, Matthes RD, Bedford TG, Maynard JA, Walmer HC An in situ study of the influence of a sclerosing solution in rabbit medial collateral ligaments and its junction strength. Connect Tissue Res. 1983;11(2-3):95-102. [PubMed: 6224646].

55. Maynard JA, Pedrini VA, Pedrini-Mille A, Romanus B, Ohlerking F Morphological and biochemical effects of sodium morrhuate on tendons. J Orthop Res. 1985;3(2):236-48. doi: 10.1002/jor.1100030214. [PubMed: 3998899]. 
Akpancar S et al.

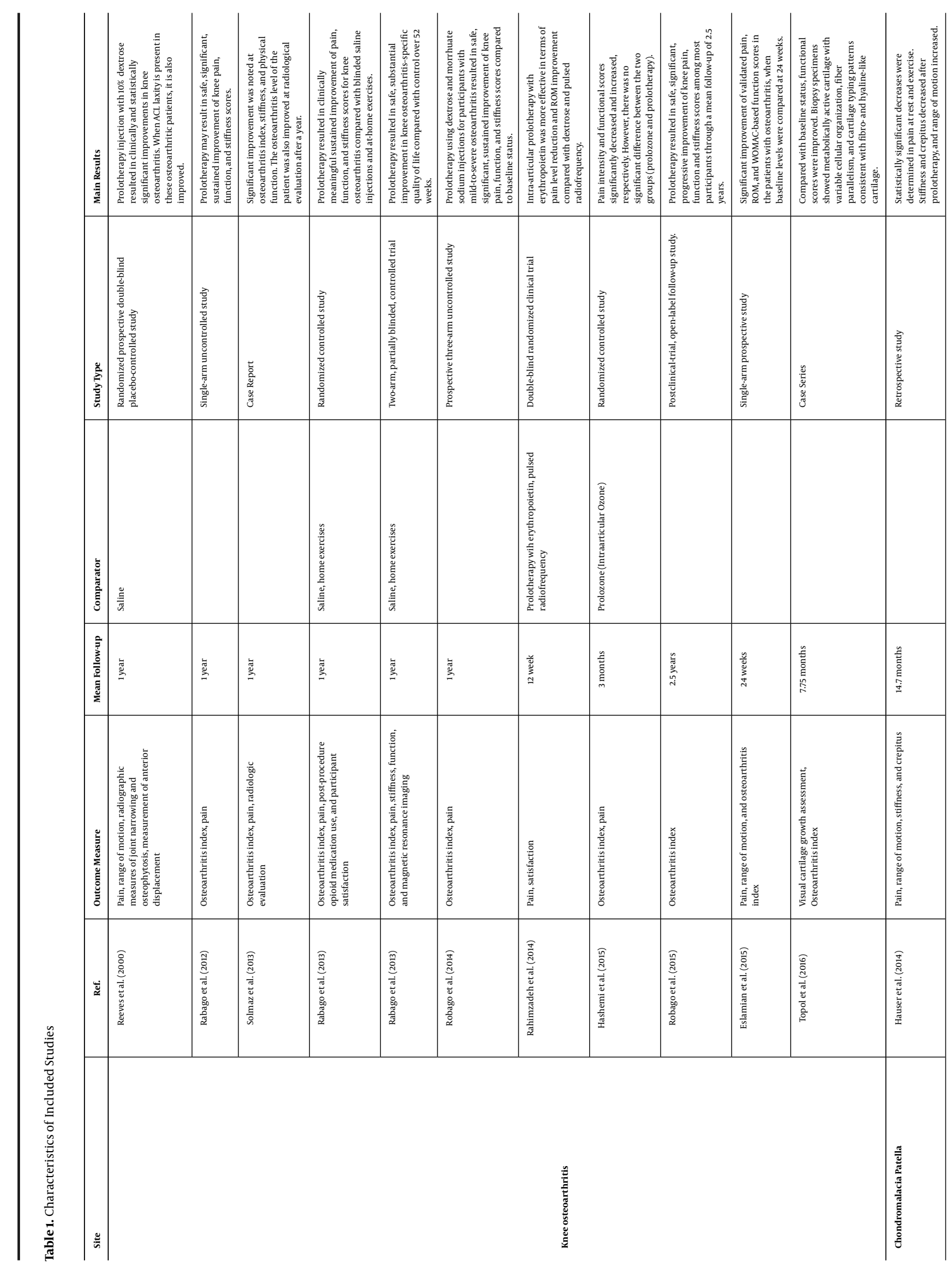

Arch Trauma Res. 2017; 6(2):e40447.

7 


\begin{tabular}{|c|c|c|c|c|c|c|c|c|c|c|c|c|c|}
\hline 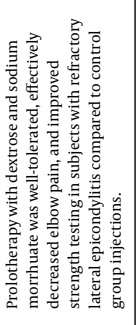 & 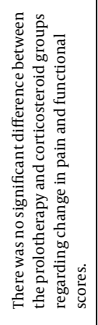 & 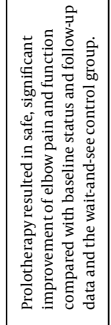 & 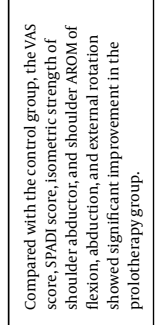 & 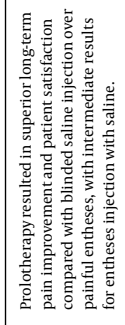 & 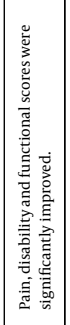 & 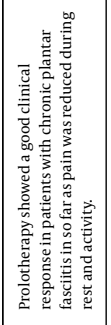 & 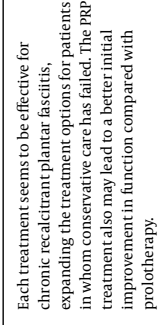 & 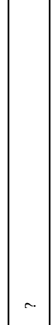 & 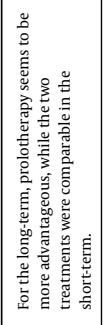 & 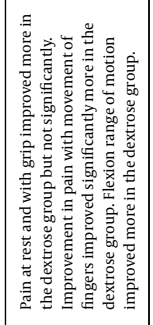 & 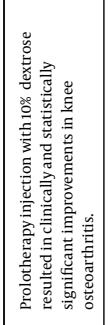 & 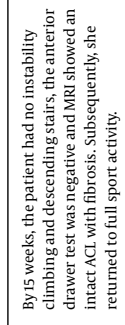 & 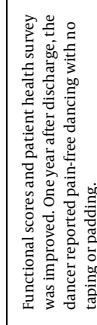 \\
\hline & 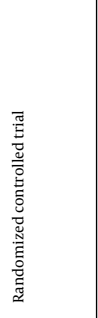 & 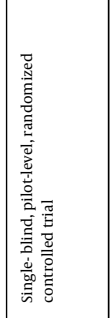 & 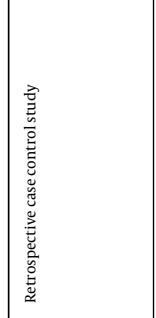 & 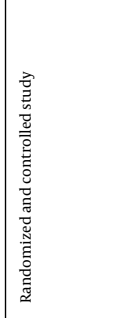 & 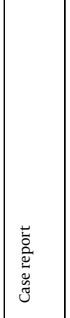 & 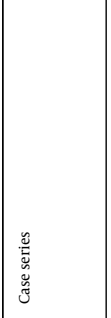 & 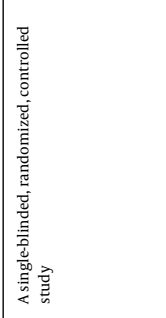 & 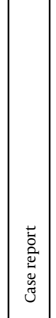 & 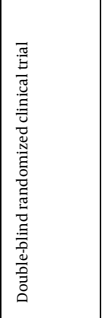 & 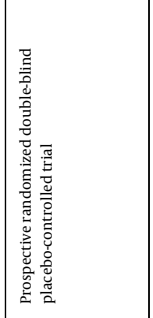 & 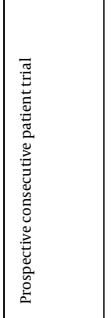 & 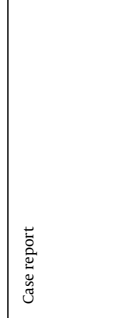 & 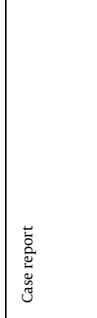 \\
\hline 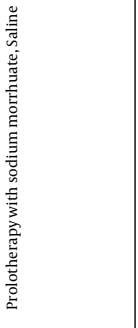 & 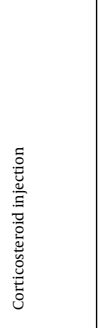 & 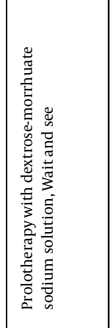 & 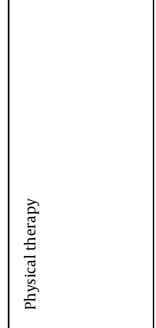 & 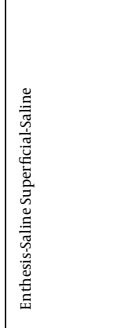 & & & 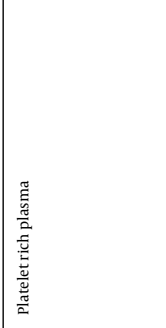 & & 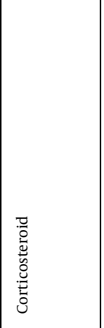 & 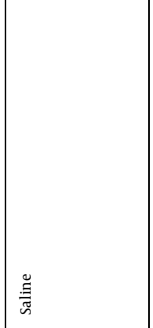 & 总 & 旁 & 咅 \\
\hline 气̆ & 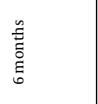 & 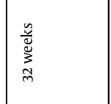 & 愛 & 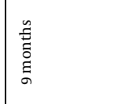 & 气 & 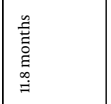 & 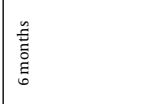 & 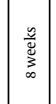 & \begin{tabular}{|l} 
善 \\
言
\end{tabular} & 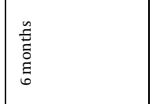 & \begin{tabular}{|l} 
总 \\
言 \\
总
\end{tabular} & 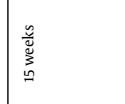 & \begin{tabular}{|l|l} 
\\
言 \\
晋
\end{tabular} \\
\hline 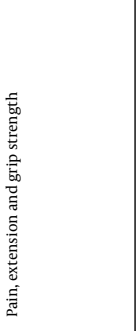 & 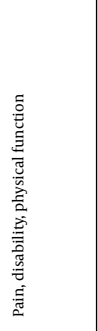 & 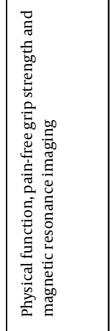 & 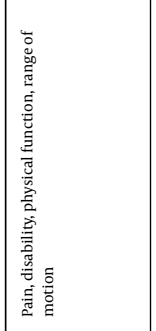 & 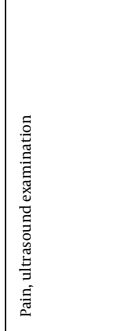 & 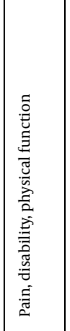 & 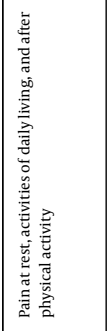 & 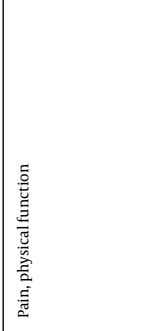 & 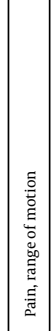 & 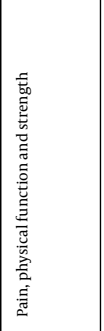 & 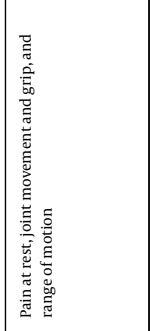 & 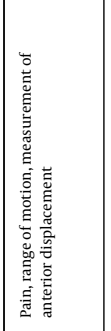 & 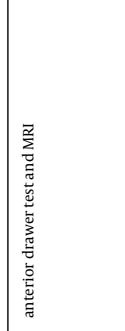 & 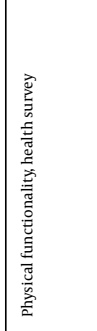 \\
\hline 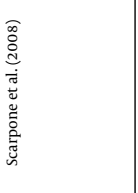 & 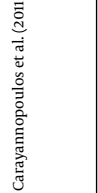 & 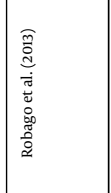 & 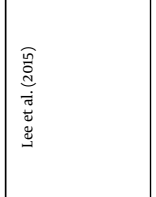 & & 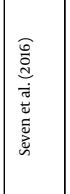 & 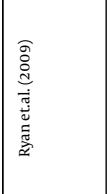 & & 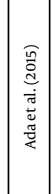 & 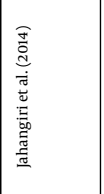 & 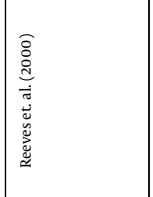 & 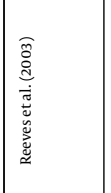 & 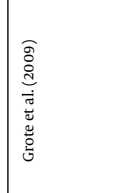 & 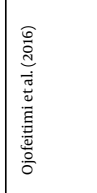 \\
\hline & 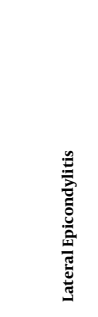 & & & 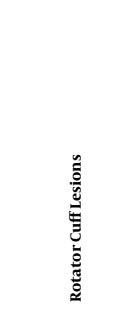 & & 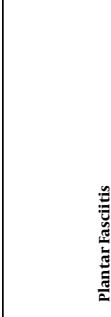 & & 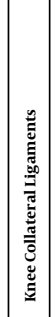 & & & 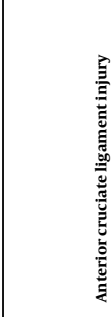 & 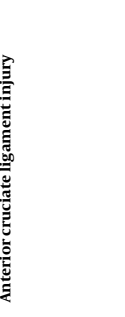 & 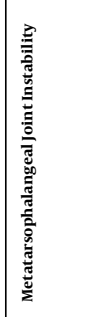 \\
\hline
\end{tabular}


